\title{
Synthesis of Ceramics in Different Colors from Industrial Waste
}

\author{
Mihail Doynov, ${ }^{1}$ Tsvetan Dimitrov, ${ }^{1}$ and Maria Kokkori ${ }^{2}$ \\ ${ }^{1}$ Razgrad Branch, Rousse University "Angel Kanchev", Aprilsko Vastanie Street 47, 7200 Razgrad, Bulgaria \\ ${ }^{2}$ The Art Institute of Chicago, 111 South Michigan Avenue, Chicago, IL 60603, USA \\ Correspondence should be addressed to Mihail Doynov; mihaildoy@abv.bg
}

Received 16 April 2013; Accepted 23 June 2013

Academic Editor: Pavlos Kassomenos

Copyright (C) 2013 Mihail Doynov et al. This is an open access article distributed under the Creative Commons Attribution License, which permits unrestricted use, distribution, and reproduction in any medium, provided the original work is properly cited.

\begin{abstract}
The synthesis of arsenic-free ceramics from industrial waste is studied. Samples of waste containing siliceous material passed the exploitation leap-guard layer shift reactor whose main oxide is $\gamma-\mathrm{Al}_{2} \mathrm{O}_{3}$ and, with the addition of natural raw materials and pure oxide, arsenic-free ceramics were synthesized with thermal and electrical properties related to the main phase of spinel group minerals; solid solutions were also formed in the process of synthesis. Insulating properties were established by successive heating and cooling of the specimen for six cycles. Electrical insulating properties were established by the method of resistance to arcing. The relative density was determined by hydrostatic method and diffusion lines of molecules at the main phase were characterized by X-ray diffraction analysis. The experimental procedures followed in this study allowed mixing on a molecular level due to the small dimensions of the crystallite which in turn explains the relatively high density.
\end{abstract}

\section{Introduction}

The wastes from our daily household, commercial activities, and industrial operations are treated at sewage treatment plants and most of the sewage sludge is landfilled after reducing the volume. Rapid growth of industrial activities and urbanization in recent years led to increase of wastes and difficulties in securing sites for landfill disposal. Thus, the conversion of sewage sludge and processing of raw materials into resources are an emerging research topic area.

To date, catalysts are used in the petroleum industry to refine processes such as the catalytic cracking, catalytic reforming, desulphurization, and the production of petrochemicals dealkylation processes. Silicate materials are also used as adsorbents and molecular sieves in the processes of gas desulphurization [1].

Several technologies have been developed to use effectively sewage sludge. In Russia, for example, colored glass (Sigran) is produced from condensed sewage sludge phosphorus. The composition of the slag system includes $\mathrm{CaO}$, $\mathrm{Al}_{2} \mathrm{O}_{3}$, and $\mathrm{SiO}_{2}$ [2]. The molten glass crystallizes at $950^{\circ} \mathrm{C}$. $\mathrm{X}$-ray diffraction analysis shows that the main phases are $\alpha$-and $\beta$-wollastonite and fluorite. The pigments used include $\mathrm{Cr}_{2} \mathrm{O}_{3}, \mathrm{Co}_{2} \mathrm{O}_{3}, \mathrm{Cu}_{2} \mathrm{O}, \mathrm{NiO}$, and $\mathrm{Sb}_{2} \mathrm{O}_{3}[3-5]$.

Green color ceramics have been synthesized from slag directly from the furnace metallurgical furnaces [5-7]. The chemical composition of slag was in \%e: $\mathrm{SiO}_{2}-50,6$; $\mathrm{CaO}-$ 14,$9 ; \mathrm{MgO}-4,4 ; \mathrm{MnO}-15,6 ; \mathrm{Na}_{2} \mathrm{O}+\mathrm{K}_{2} \mathrm{O}-3-5,5 ; \mathrm{Al}_{2} \mathrm{O}_{3}-$ $8 \div 10 ; \mathrm{FeO}-0,3 \div 0,6 ; \mathrm{S}^{2-}-0,6 \div 12$.

Up to now, a number of reports have been published on glass-ceramics using waste materials such as slag; however, these technologies often face problems with cost and quality.

This study focuses on the synthesis of ceramics from a mixture of waste catalysts and natural raw materials such as slag, cullet, and dolomite. Dolomite $\left(\mathrm{CaMg}\left(\mathrm{CO}_{3}\right)_{2}\right)$ is an important source of $\mathrm{Ca}$ and $\mathrm{Mg}$, necessary for the synthesis of diopside $\left(\mathrm{CaMgSi}_{2} \mathrm{O}_{6}\right)$ and anorthosite $\left(\mathrm{CaAl}_{2} \mathrm{Si}_{2} \mathrm{O}_{8}\right)$ which are the main phases of the manufactured ceramics and its addition improves crystallinity and strength. The mechanism of the synthesis has been studied using a range of analytical techniques including differential thermal analysis (DTA), X-ray diffraction (XRD), and scanning electron microscopy coupled with energy dispersive X-ray spectroscopy (SEM/EDX). Making waste nonhazardous and creating a resource could add a high value to the field. 
TABLE 1: Oxide compositions of raw stock.

\begin{tabular}{|c|c|c|c|c|c|c|c|c|c|c|c|c|c|}
\hline \multirow{2}{*}{ Model number } & \multicolumn{13}{|c|}{ Oxides, mass\% } \\
\hline & $\mathrm{SiO}_{2}$ & $\mathrm{Al}_{2} \mathrm{O}_{3}$ & $\mathrm{CaO}$ & $\mathrm{MgO}$ & $\mathrm{Na}_{2} \mathrm{O}$ & $\mathrm{K}_{2} \mathrm{O}$ & $\mathrm{Fe}_{2} \mathrm{O}_{3}$ & $\mathrm{TiO}_{2}$ & $\mathrm{MnO}$ & $\mathrm{P}_{2} \mathrm{O}_{5}$ & $\mathrm{SO}_{3}$ & $\mathrm{~B}_{2} \mathrm{O}_{3}$ & As \\
\hline $\begin{array}{l}1 \\
35 \% \text { catalyst }\end{array}$ & 50.35 & 12.00 & 12.10 & 1.50 & 1.90 & 2.80 & 6.80 & 0.50 & 0.05 & 0.05 & 0.70 & 0.70 & 10.55 \\
\hline $\begin{array}{l}2 \\
30 \% \text { catalyst }\end{array}$ & 54.80 & 7.00 & 15.90 & 1.10 & 2.50 & 1.70 & 4.20 & 0.30 & 0.03 & 0.03 & 0.40 & 0.90 & 11.14 \\
\hline $\begin{array}{l}3 \\
25 \% \text { catalyst }\end{array}$ & 56.00 & 6.70 & 16.10 & 0.90 & 2.80 & 1.90 & 3.30 & 0.20 & 0.02 & 0.02 & 0.30 & 1.20 & 10.56 \\
\hline
\end{tabular}

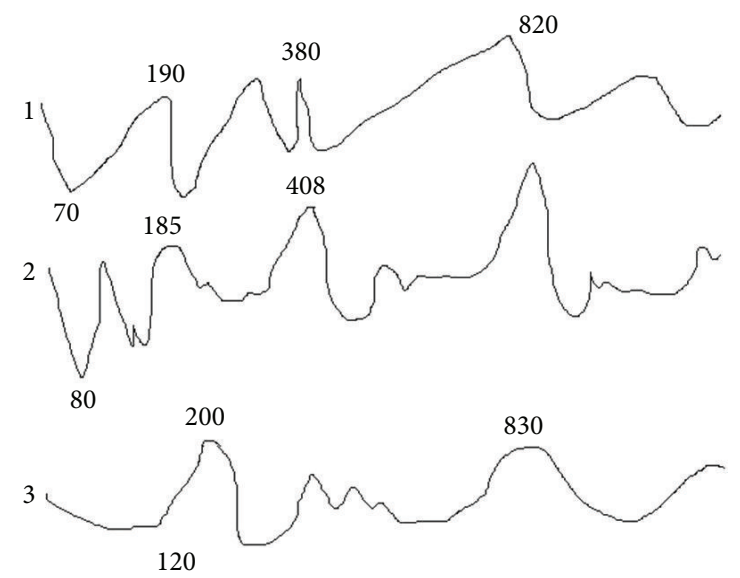

Figure 1: DTA curves of the synthesized powders $\left(0-1000^{\circ} \mathrm{C}\right)$. The powders were further compressed and ceramic samples were prepared for testing.

\section{Experimental Procedure}

The raw materials including sand, water, glass, trass, and exhaust catalyst crackers of vacuum gas oil selected and tested for the initial composition of ceramic materials are listed in Table 1.

A major problem in the utilization of this type of industrial waste is the presence of arsenic which can harm the final product, affecting quality control. Therefore, these catalysts are deposited after the end of their lifetime.

Raw materials were blended and grounded in a mill to a fineness of less than $1 \mu \mathrm{m}$ and subjected to heat treatment at a retention temperature of $350^{\circ} \mathrm{C}$ for one hour. The powder was homogenized using ethyl alcohol tablet and fired at a temperature of $600-1100^{\circ} \mathrm{C}$, with isothermal retention temperature for $0.5,1,1.5$, and 2 hours.

The process of heat treatment was held in silite electric furnace at a temperature increase at $400^{\circ} \mathrm{C} / \mathrm{h}$. The temperature carried out in the experiment represents the isothermal retention of homogenization. The color of the resulting glass composition is determined by RGB systems (Table 2). Crystallization was carried out to obtain flat and tight plates. Due to the heat treatment the first supernatant fine fraction was in a closed cavity with air. For their separation it was necessary for fractions to be prehomogenized and compacted by vibration. This led to the formation of dense products without pores that exhibited high strength. After heat treatment,
TABLE 2: Typical ratios of RGB colors (R: red; G: green; B: blue; $H^{*}$ : color hue; $S^{*}$ : saturation; $V^{*}$ : brightness $\left(H^{*}, S^{*}\right.$ and $\left.V^{*}-0 \div 360^{\circ}\right)$ ).

\begin{tabular}{lcccccc}
\hline \multirow{2}{*}{ Model } & \multicolumn{7}{c}{ Color ratios } \\
& $\mathrm{R}$ & $\mathrm{G}$ & $\mathrm{B}$ & $H^{*}$ & $S^{*}$ & $V^{*}$ \\
\hline 1 & 0.437 & 0.320 & 0.135 & 30 & 0.685 & 0.439 \\
2 & 0.417 & 0.296 & 0.124 & 30 & 0.685 & 0.414 \\
3 & 0.353 & 0.259 & 0.115 & 30 & 0.685 & 0.351 \\
\hline
\end{tabular}

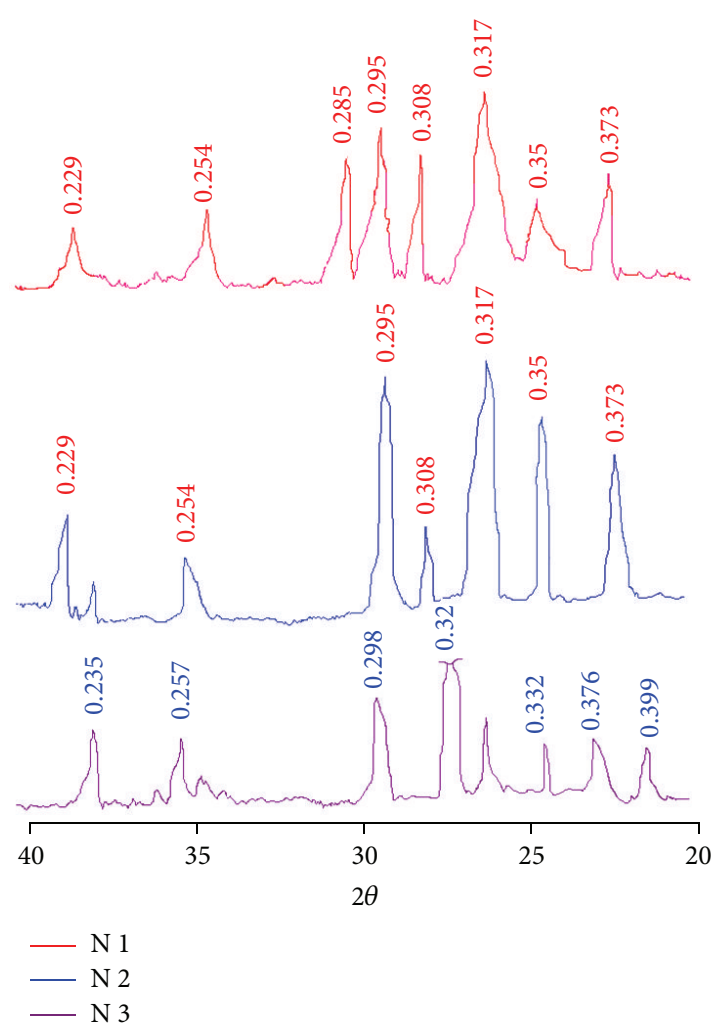

FIGURE 2: X-ray diffraction of synthesized ceramic samples at $1000^{\circ} \mathrm{C}$ for $1 \mathrm{~h}$.

the manufactured ceramics were analysed using X-ray diffraction, differential thermal analysis, and scanning electron microscopy.

Figure 1 shows the measured results using differential thermal analysis. The differential thermal analysis curves represent the endoeffects at $70^{\circ} \mathrm{C}, 190^{\circ} \mathrm{C}$, and $830^{\circ} \mathrm{C}$, respectively; when the amount of catalyst (waste) is reduced, the curves are shifted to the right, which indicates that synthesized powders 


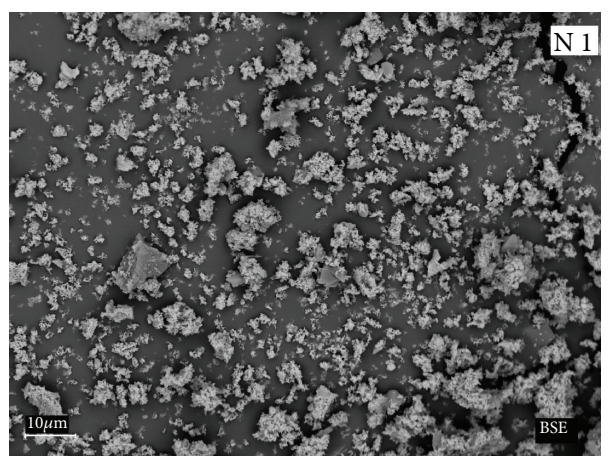

(a)

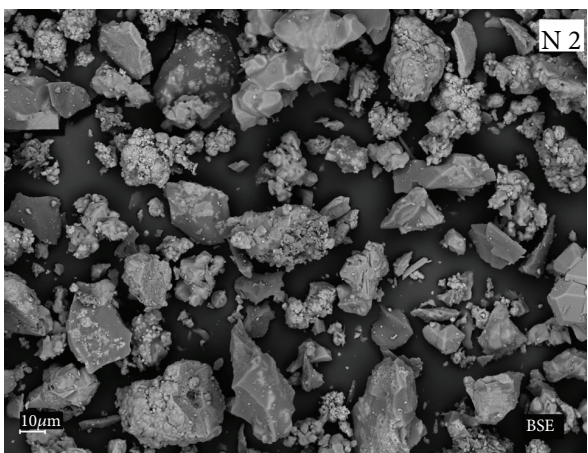

(b)

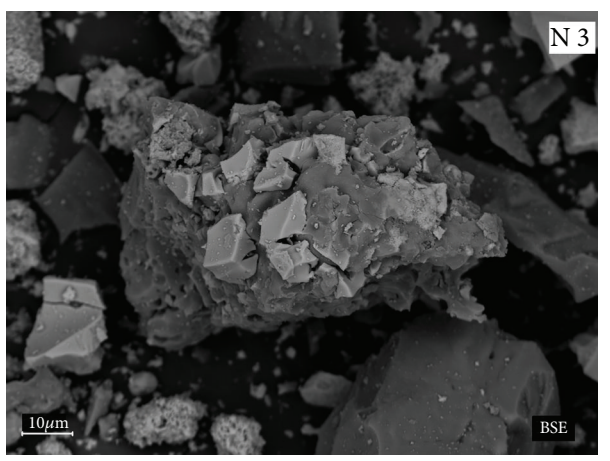

(c)

FiguRE 3: Backscattered electron micrographs of ceramic samples.

act themselves as catalysts. Exoeffects at $80^{\circ} \mathrm{C}$ and $120^{\circ} \mathrm{C}$ are related to the decomposition of residual moisture (water related) remained in the disposal of waste.

\section{Results and Discussion}

Earthenware was synthesized from natural raw materials and waste catalyst. The waste obtained after thermal treatment contained arsenic originated from the catalyst system for cracking of vacuum gas oil.

As shown from the DTA analyses carried out on heattreated powders, in a range of temperatures up to $1150^{\circ} \mathrm{C}$ the crystallization curve exothermic time is within the range of $900-1100^{\circ} \mathrm{C}$. X-ray diffraction analysis of the powders shows prismatic precipitated crystals of diopside as the main crystalline phase. The energy calculated by the Kissinger method of crystallization was $360 \mathrm{~kJ} / \mathrm{mol}$ and the Abraham parameter 1.66, which depends on the load-step controlled diopside crystals [8-11].

In all synthesized materials several decorative effects were observed due to the presence of amorphous and crystalline phases that refract and reflect light in numerous ways. This leads to a good aesthetic appearance of the final product. $\mathrm{X}$-ray analysis is a suitable technique for the study the crystallization phases. X-rays, able to penetrate dust, were produced using $\mathrm{CuK}_{2}$ radiation with nickel filter at a speed of rotation $4^{\circ} / \mathrm{min}$.

From the X-ray diffraction chart of Figure 2, the main crystals identified in the manufactured ceramics can be confirmed to be composed of anorthite and quartz with characteristic lines for the crystalline phases $(\mathrm{d}, \mathrm{nm})$ for anorthite $(0.319 ; 0.298 ; 0.285 ; 0.235)$ and quartz $(0.332 ; 0.246$; $0.210)$. In a composite sample two main crystalline phases $(\mathrm{d}, \mathrm{nm})$ were identified as wollastonite $(0.383 ; 0.308 ; 0.350$; $0.272 ; 0.254)$ and second phase $\alpha$-tridymite $(0.295 ; 0.246$; 0.229 ). The composite 1 is characterized by the presence of two crystalline phases $(\mathrm{d}, \mathrm{nm})$, wollastonite and frilengenite (0.285; 0.307; 0.221). The spectral lines are characteristic of the solid solutions: $\mathrm{MgAl}_{2} \mathrm{O}_{4}+\mathrm{CoAl}_{2} \mathrm{O}_{4}$ and $\mathrm{NiAl}_{2} \mathrm{O}_{4}+$ $\mathrm{ZnAl}_{2} \mathrm{O}_{4}$. These solid solutions are responsible for the colors of the ceramics whose average particle size is $200 \mu \mathrm{m}$.

Figure 3 shows the photographs of fractured sections of manufactured ceramics taken with the scanning electron microscope. Numerous prismatic crystals are entangled and precipitated.

Conducted experiments on frost resistance showed resistance at 6 cycles. The arsenic catalyst was not identified in the final products, indicating that either it was connected into the cubic grid spinels compounds or was removed and subsequently not involved in the reactions. More likely is that it was encapsulated in a cubic crystal lattice.

\section{Conclusions}

This research has demonstrated the synthesis processes of hard, arsenic-free ceramics in different colors from industrial waste materials containing arsenic catalysts and natural raw materials through heat press and firing procedures. 
The manufactured ceramics were high in strength having good physical and visual properties.

\section{Acknowledgment}

The authors thank the Bulgarian Ministry of Education and Science, Fund "Scientific Investigation" Project DDVU02_32/2010 for financing this project.

\section{References}

[1] J. Emberton and A. Parker, "The problems associated with building on landfill sites," Waste Management \& Research, vol. 5, no. 4, pp. 473-482, 1987.

[2] R. Siemens, B. W. Jong, and J. H. Russell, "Potential of spent catalysts as a source of critical metals," Conservation \& Recycling, vol. 9, no. 2, pp. 189-196, 1986.

[3] "Reinforceable sintered glass-ceramics," United States Patent no. $4892846,1988$.

[4] J. Drexler, A. L. Ortiz, and N. P. Padture, "Composition effects of thermal barrier coating ceramics on their interaction with molten $\mathrm{Ca}-\mathrm{Mg}-\mathrm{Al}-$ silicate (CMAS) glass," Acta Materialia, vol. 60, no. 15, pp. 5437-5447, 2012.

[5] W. Hammetter and R. E. Loehman, "Crystallization kinetics of a complex lithium silicate glass-ceramic," Journal of the American Ceramic Society, vol. 70, no. 8, pp. 577-582, 1987.

[6] B.-H. Lee, "Method of preparing a green-ceramic pigment for reduction firing using copper oxide and a green ceramic made thereby," US 20100304031 Al, 2010.

[7] S. Tang, Z. Liang, and G. Chen, "Crystallisation heat treatment of an antimony containing slag glass ceramic," Glass Technology, vol. 36, no. 2, pp. 61-64, 1995.

[8] E. Bernardo, R. Castellan, S. Hreglich, and I. Lancellotti, "Sintered sanidine glass-ceramics from industrial wastes," Journal of the European Ceramic Society, vol. 26, no. 15, pp. 3335-3341, 2006.

[9] I. Rozenstrauha, D. Bajare, R. Cimdins, L. Berzina, J. Bossert, and A. R. Boccaccini, "The influence of various additions on a glass-ceramic matrix composition based on industrial waste," Ceramics International, vol. 32, no. 2, pp. 115-119, 2006.

[10] Y. J. Park and J. Heo, "Corrosion behavior of glass and glassceramics made of municipal solid waste incinerator fly ash," Waste Management, vol. 24, no. 8, pp. 825-830, 2004.

[11] A. A. Francis and N. F. Youssef, "Glass-ceramic from industrial waste materials," Scandinavian Journal of Metallurgy, vol. 33, no. 4, pp. 236-241, 2004. 

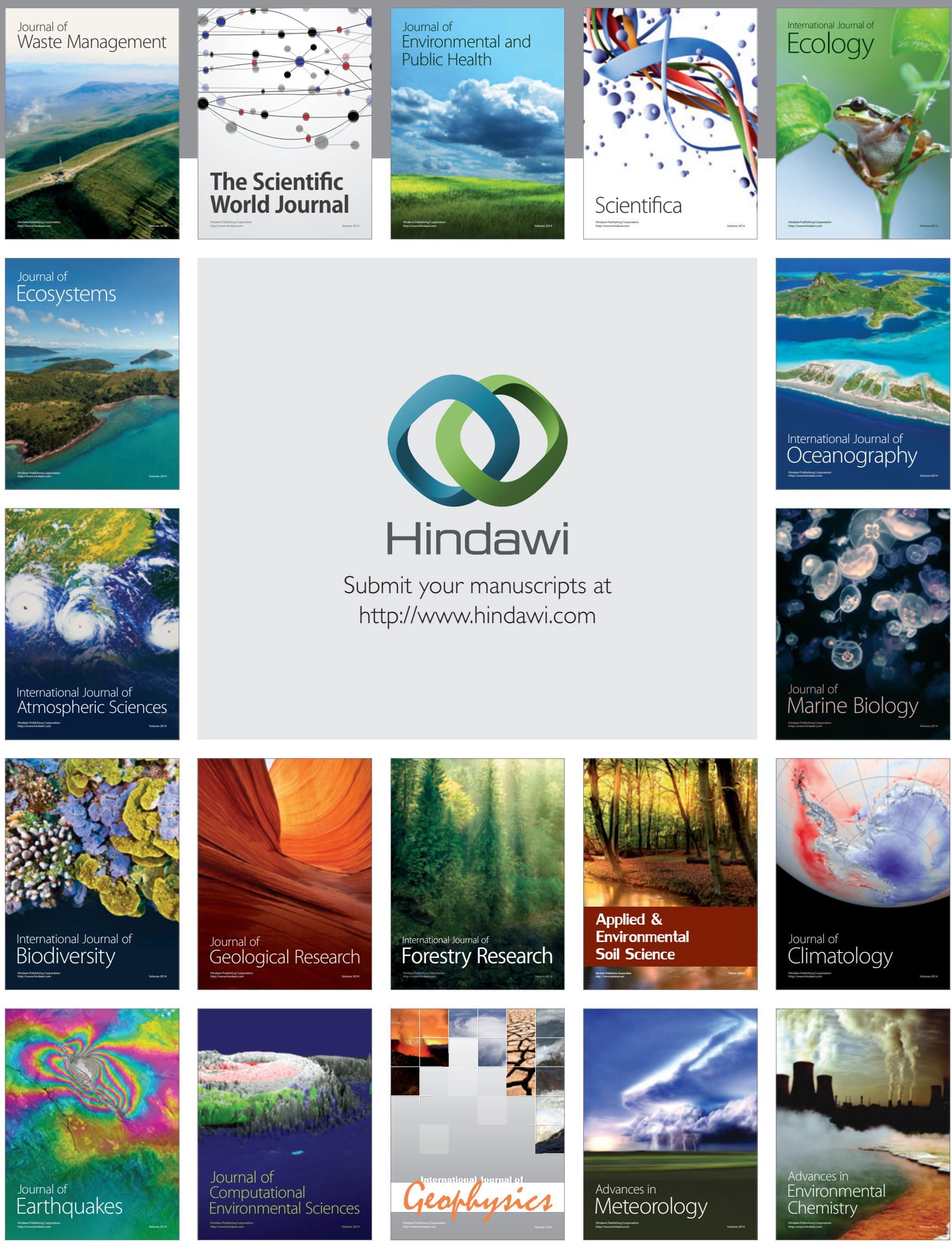